\title{
$\nabla$ Power, Autonomy and Emotional Well-Being in Later Life: A Qualitative Study in Rural Assam, India
} IJCRR
ection: Healthcare
ISI Impact Factor
$(2019-20): 1.628$
Value (2019): 90.81
SJIF (2020) = 7.893
Cc) (i) (8)
Copyright@IJCRR

\section{Nitish Gogoi ${ }^{1}$, Shashank Yadav²}

'PhD Scholar, Department of Sociology, Tezpur University, Assam 784028, India.; 'Assistant Professor and Head, Department of Sociology, Rajiv Gandhi University, Arunachal Pradesh, India.

\section{ABSTRACT}

Introduction: There is always a strong correlation between power, autonomy and emotional well-being. A person with full autonomy can determine his/her potentiality, feel free to do whatever they wanted to do and able to evaluates their 'self' by personal standards.

Objective: To assess the impact of autonomy and power in the emotional well-being among the aged population living in a traditional rural cultural context. And also to observe the impact of modernity and changing social values and its impact on family integration and the emotional well-being of elderly people.

Methods: Abductive research strategy has been prepared for this study with its tools and techniques in collecting and analysing data. For the study total of 15 respondents (comprised of 8 aged males and 7 aged females) has been selected in the age group of 60 and above from the selected villages and conducted qualitative in-depth interviews. In the next phase total of 3 focus group discussions (FGDs) have been organized. An active non-participant observation has also been made during the whole study. Finally, Narrative Analysis (NA) has been done to analyse the data.

Results: The results reveal that the elderly's emotional well-being is positively associated with their power and autonomy within the family. Elderly with full power and autonomy within the family were enjoying strong emotional well-being than the aged with less power and autonomy. However, the elderly's socio-economic background has a serious impact on the construction of emotional well-being among the aged population being investigated. Also, gender differences have been observed throughout the study.

Conclusion: Thus, the study identified power and autonomy as the significant element of emotional well-being in later life.

Key Words: Aged, Autonomy, Emotional Well-being, Power, Qualitative Study, Rural

\section{INTRODUCTION}

Power and autonomy have always been a major element of emotional well-being among the aged population in a traditional society like India. Traditionally, India has a unique family system where three or four generations lived in the same household. The family in India joint in nature where elderly people lived with more respect and honour and it was believed that they are resourceful and more knowledgeable person. They are also enjoying autonomy and decision making responsibility within the family. Under their responsibility, the functions of the family were smoothly run. The young generations also abiding by the values and responsibilities given by their elderly parents or grandparents. Under the guidance of older generations, the young generations were able to find a meaningful path in their life. The solidarity was very strong across the generations. And it contributed to aggrandize the life satisfaction and well-being of both generations. However, in the past three decades, many changes have been taken place in traditional family values cause by modernization, urbanization and mostly migration of the young generation in search of various job opportunities hampered the traditional family values. It is also predicted that with the increasing demand for workforce participation the relationship across generations become more materialistic than ever before and have weakened the intergenerational bonds and structure and functions of the family as well.

Corresponding Author:

Nitish Gogoi, PhD Scholar, Department of Sociology, Tezpur University, Assam 784028, India.

Phone: 8638213652; Email: nitishgogoi50@gmail.com

ISSN: 2231-2196 (Print)

ISSN: 0975-5241 (Online)

Received: 23.10 .2020

Revised: 12.12 .2020

Accepted: 03.02.2021

Published: 25.04 .2021 
Nowadays, in India due to the loss of their autonomy and power within the family, the elderly people are surviving, and on the other hand, protesting and opposing attitudes become common among the young generations and it increases the gap between generations. In this changing scenario, the old people become isolated and faced difficulties to cope with the changing situations and get marginalized. Various issues and challenges coming up with the rapid changes in family relations. With the breakdown of generational solidarity, the level of depression has been increasing among the older generations and due to intergenerational conflict, the problem of loneliness arises as to the major threat to the emotional/ mental and physical well-being of elderly people. There are many instances where loneliness leads to suicides among the older generations. Thus, the older generation is eventually losing their authority and power within their intergenerational family relation. And it has a great impact on the overall well-being of elderly people. The present paper is an attempt to assess the impact of authority and power on the emotional well-being of the aged population living in a traditional rural cultural context. Furthermore, throughout the study, an attempt has also been made to observe the impact of modernity and changing social values and its impact on family solidarity and integration and the emotional wellbeing of elderly people.

\section{MATERIALS AND METHODS}

The study has been done from November 2019 to January 2020 in the Dibrugarh district of Assam, India. Total three villages i.e., Genichuk, Hahoyal and Bogoritoliya have been selected purposefully and an abductive research strategy has been prepared for this study with its tools and techniques in collecting and analysing data. Abductive research strategy's starting point is the social world of social actors being investigated, their social construction of reality and their meaning giving process to their social world. For the study total of 15 respondents (comprised of 8 aged males and 7 aged females) has been selected in the age group of 60 and above from the selected villages and conducted qualitative in-depth interviews. Their narratives have been recorded with their verbal and written consent. In the next phase total of 3 focus group discussions (FGDs) have been organized and given full opportunities to share their experiences and perspectives on the investigated topic. An active non-participant observation has also been made during the whole study. Finally, Narrative Analysis (NA) has been done to analyse the data. Narrative inquiry refers to a subset of qualitative research designs in which stories are used to describe human action. The term narrative has been employed by qualitative researchers with a variety of meanings. ${ }^{1}$ Thus narrative inquiry can be an approach that is most relevant to understanding the experiences, actions, motivations, and life journeys of people who are challenged by health, disability, trauma, change, adaptation, loss, or other significant life challenge. ${ }^{2}$

\section{RESULTS AND DISCUSSION}

\section{Emotional Well-being in Later Life: The Role of Autonomy and Power}

There is always a strong correlation between power, autonomy and emotional well-being. A person with full autonomy can determine his/her potentiality, feel free to do whatever they wanted to do and able to evaluates their 'self' by personal standards. Therefore, the elderly's emotional well-being has been measured by their autonomy and power within intergenerational relation with the help of a question, "Do you feel that autonomy and power in family help to foster your emotional well-being?" And it was revealed that all the respondent has been enjoying more or less autonomy and power as head of the family and it fosters their emotional wellbeing. No one has reported conflict-related to autonomy and decision making in their family matters. They have always been receiving priority while taking any decision by their younger children. Budhiram Dutta, a 65 years aged male respondent from Genichuk village happily narrated that:

"I am very happy to say that I have been enjoying full autonomy and power in my family. As ahead of the family, it's my privileged to have such respect from my children and other family members. It's not like that I am controlling their autonomy and freedom, but this is just the matter of respect and privileged that fosters my emotional well-being in later part of my life".

It was also observed that aged person with full autonomy and power were more likely to report strong emotional wellbeing as compared to the elderly with less autonomy and power. However, socio-economic background such as economic dependency, health, co-residence etc., has also been played a significant role in the construction of their emotional well-being. Our study reveals that aged those who are in the age group of 60 to 65 with the good economic condition and with excellent health were enjoying more autonomy and power than those who are in the age group of 80 and above with no income and poor health. Few respondents have been enjoying less autonomy and power within the family. However, they have reported an alternative standpoint in the construction of their emotional well-being. They are of the view that they just need emotional ties among family members and children and they need emotional support in their later life. For them, strong family ties and bonding is the core instrument to nurture emotional well-being than autonomy and power. For instance, Kuhiram Das, a 76 years old aged male respondent from Bogoritoliya village narrated that: 
"What is more important for me is strong family ties and bonding among my family members. Yes, of course, as ahead of the family I wants to hold my family in my hand but the more I grow the more I feel that strong solidarity among family members is more important than my power and autonomy in my family".

Therefore, their family background and family environment have also made a serious impact on their emotional wellbeing. In a study, it was reported that there was a significant direct effect of living environment on the relationship between parents and children and has an indirect effect on attitudes towards ageing. ${ }^{3}$ Similarly, another study also reported that the quality of the family relationship has been greatly influencing by the positive change in the living environment. A positive living environment improves both life satisfaction and the quality of the family relationship. ${ }^{4}$ Therefore, it can be said that the residential environment can be an important element of positive family relationship and the emotional well-being of elderly people.

However, gender differences have been observed throughout the study. Because it was the aged male who wants more power and autonomy in their family than their female counterparts. During the interview, it was the aged male who is more vocal about their family. The existing gender power structure has also been reflected during the interview with female respondents. They are less likely to speak in their family, but significantly, more likely to have strong bonding with their children. Almost all the aged female respondents are of the view that they just need love, care, and attention from their children and other family members. For love and care works more than medicines. Pushpeswari Dutta, a 69 years old female respondent from Hahoyal village narrated that:

"What I need from my children are more love, care and some kindness and that's enough for me to foster my emotional well-being than autonomy and power. Although, I am enjoying autonomy and power as ahead of the family that does not matter for me if there is no love and respect in that power".

Moreover, all the respondents are of the view that both instrumental and expressive support from the family members is a significant element of emotional well-being. However, in many studies, it was found that parents want to minimize the amount of support received from children as it increases their dependency on children and hence they wanted to avoid the stigma of being a 'burden'. ${ }^{5}$ For instance, a study on the 'Public perception of care giving' reported that old parents don't want to be a burden on their children. Respondents believe that they want to be independent as long as their functional capacity permits. And it was also revealed that older parents mostly prefer to live by themselves than with their children's families or in other institutions like old age home. ${ }^{6}$

\section{Paradoxes of Modernity}

The changing social values and rapid transformation in the family structure has a serious impact on the overall well-being of the aged population in India. There was a time when elderly people were taken care of by their children or other family member and they have lived a healthy life within the family. But nowadays with increasing materialistic values the young generation today holds the attitudes toward elderly as economically unproductive and hence some children even don't hesitate to send their aged parents to old age home or other institution. India Aging Report of 2017 presenting four challenging aspects of ageing in India- First, according to the report, discrimination and neglect towards women, and dependence on others lead to the Feminization of Aging. Also, the loss of a spouse hurt the well-being of elderly women. Due to the dependence on others the older women, today lived in a vulnerable situation than older men. Because the young children today don't show their willingness to take care of their old and economically unproductive parents. Secondly, in comparison to other developed countries, the majority of the older population live in villages with poor transportation and communication facilities i.e., Ruralization of the Elderly. Though the modern means of medical technology has been increasing in India still the elderly in India are living in rural areas far away from the advanced medical facilities. The income insecurity, quality health care, isolations are more vulnerable to rural elder than their urban counterparts. Third, the report said that the number of older women increasing than older men in India due to the early marriage and loss of a spouse in their mid-life i.e., it is projected that India will have more than 80 plus women and hence the older women become survivor within the family. Finally, in India like other countries in the world, the young generations are migrated for workforce participation and it had a significant impact on intergenerational family relations. ${ }^{7}$ It is not always true that the migration of the younger generation harms the well-being of elderly people. Even according to the report the migration of younger generations enhances the well-being through monetary support to elderly parents in need. However, it also leads to the problems of loneliness among elderly parents.

In the present study, throughout the focus group discussions (FGDs) full liberty has been given to the respondents to share and discuss their views regarding the changing family values and their impact on their emotional well-being. Significantly most of the respondents think that they have to go with the changing social values although they don't like modern mores and values in their family and society as well. Some are of the view that they are losing their autonomy and power due to modern ways of lifestyle and habits embedded by their younger children. Whereas, some female respondents are of the view that sometimes they have to adjust to the decision taken by their children as otherwise, it will create 
conflict between them. Pravat Dutta, from Hahoyal village, shared his experiences and narrated that:

"Sometimes we have to listen to our children and other family members' needs and attitudes and have to adjust with their modern values. Although we are still practising our old age traditions sometimes we also have to sacrifice them for the sake of our younger generations. Because it helps to maintain peaceful family environment". ${ }^{10,11}$

All the respondents think that their children may not like their controlling attitude. Significantly, it was observed that the elderly with highly rigid attitudes had problems in adjustment with their children, and had less interaction or no interaction with children. Conflict occurs between generations due to the different attitudes towards societal values. In a study, it was reported that differences in interest, likes, dislikes, differences in attitude and lifestyle are the root cause of the generation gap. It was found that protesting and opposing attitudes were common among the youths and they prefer to live with their own chosen will. ${ }^{8}$

\section{CONCLUSION: TOWARDS A HEALTHY AGING}

The findings of the present study suggest that future study should give its importance on the socio-economic background of the aged population in the study of family relation. Because the pattern of exchange of both instrumental and expressive support was varied according to the socioeconomic variables of the respondents. However, power and autonomy have been identified as significant indicator of emotional well-being in later life. All the elderly in the present study have been showing higher morale, mostly experiencing a very friendly environment within their family. They have been taken care of by their children, have a friendly interaction with children and getting proper attention from their children. In addition to this, old age is also known as the second childhood where they required some love, care, and attention and it makes them very happy. Therefore, for the emotional well-being of elderly people, the young children, as well as the other family members, should try to make the aged friendly environment within the family. Family members, children should give some autonomy to their aged par- ents to live their life according to their desire. Every family indeed have some conflict regarding family matters when the aged parent remains rigid in their mindset and do not accept the lifestyles, radical views, and modernity followed by their young children. But sometimes the young generation should agree with the decision taken by their aged parents keeping in mind the aged parent's cultural context of life.

\section{ACKNOWLEDGEMENT}

We are very grateful to the anonymous reviewers for their critical insights on the earlier version of the manuscript.

Conflict of Interest: We don't have any conflict of interest.

\section{REFERENCES}

1. Polkinghorne, Donald E. Narrative Configuration in Qualitative Analysis. Int J Qualit Stud Edu 1995;8 (1):5.

2. Sharp NL, Bye RA, Cusick A. Narrative Analysis, in: P. Liamputtong (Eds.), Handbook of Research Methods in Health Social Sciences. Springer Nature Singapore Pte Ltd. 2019.

3. Johnson ES. Good Relationships Between Older Mothers and their Daughters: A Causal Model. Gerontology 1978;18;301306.

4. Carp FM. The Impact of the Environment of Old People. Gerontology 1967;7:106-108, 135.

5. Bengtson VL, Kuypers JA. Generational Difference and the 'Developmental Stake'. Aging Human Dev 1971;2:249-260.

6. Bengtson VL, Black KD. Intergenerational Relations and Continuities in Socialization, in: Baltes P and Schaie K. W (Eds.), Life-span Development Psychology: Personality and Socialization. Academic Press: New York. 1973; 207-234.

7. Townsend AL, Poulshock SW. Intergenerational Perspectives on Impaired Elders' Support Networks. J Gerontol 1986;41:101109.

8. Devi J. Public Perceptions on Care Giving: Then (1984) and Now (1997): An Evaluation, in: Indrani Chakravarty (Eds.), Life in Twilight Years. Kolkata. 1997;365- 374.

9. India Ageing Report. Caring for Our Elders: Early Responses. United Nations Population Fund (UNFPA). 2017: 4, 8, 9. https:// india.unfpa.org/sites/default/files/pub-pdf

10. Ramamurti PV. Intergenerational Relations, in: K. R. Gangadharan (Eds.), Aging in India: Emerging trends and Perspectives, Heritage Hospital, Hyderabad, 2002; 24-26. 